\title{
Photon treatment effect on the surface and figure of merit of thermoelectric material $\mathrm{Bi}_{2} \mathrm{Te}_{3-x} \mathrm{Se}_{x}$
}

\author{
E. Belonogov ${ }^{1,2} \cdot$ A. Grebennikov ${ }^{1} \cdot$ V. Dybov ${ }^{1} \cdot$ S. Kannykin ${ }^{2} \cdot$ A. Kostyuchenko ${ }^{1} \cdot$ S. Kuschev ${ }^{1} \cdot$ D. Serikov ${ }^{1}$. \\ S. Soldatenko ${ }^{1,3} \cdot$ M. Sumets $^{2}$ (I)
}

Received: 14 August 2019 / Accepted: 28 December 2019 / Published online: 6 January 2020

(C) The Author(s) 2020

\begin{abstract}
The phase composition, structure, morphology, and thermal conductivity of $\mathrm{Bi}_{2} \mathrm{Te}_{3-x} \mathrm{Se}_{x}$-based semiconductor solid solution after photon treatment (PT) were studied by X-ray diffractometry, SEM, TEM, and the laser flash techniques. It was revealed that $\mathrm{PT}$ leads to recrystallization of the subsurface layers of the solid solution with the formation of a heterogeneous nanocrystalline structure. The thermoelectric figure of merit of the semiconductor $\mathrm{Bi}_{2} \mathrm{Te}_{3-x} \mathrm{Se}_{x}$ (n-type) solid solution increases after PT due to modification of the surface layers. This is due to the decrease of the thermal conductivity of the studied material after PT.
\end{abstract}

Keywords Photon treatment · Surface modification · Phase composition - Thermal conductivity · Figure of merit

\section{Introduction}

Semiconductor thermoelectric materials, based on $\mathrm{Bi}_{2} \mathrm{Te}_{3}-\mathrm{Bi}_{2} \mathrm{Se}_{3}$ and $\mathrm{Sb}_{2} \mathrm{Te}_{3}-\mathrm{Bi}_{2} \mathrm{Te}_{3}$ solid solutions, and having the high thermoelectric figure of merit (ZT), pose prospects in a wide range of applications in the devices, converting thermal energy into electrical energy at the temperature range of 300-600 K [1-5]. Specifically, great progress has been achieved in energy harvesting [6-8]. Nowadays, the efficiency requirements for thermoelectric materials have increased greatly. Thus, the task of maximizing the potential of these materials is of great interest. The main requirements, determining the high thermoelectric efficiency of the materials, have been already formulated by Ioffe [9]. According to these requirements, there are two ways to increase $Z T$ : setting an appropriate elemental composition (the composition of the thermoelectric materials should maximize the ratio of electrical conductivity to the

M. Sumets

maxsumets@gmail.com

1 Voronezh State Technical University, Prosp. Moskovskij, 14, 394000 Voronezh, Russia

2 Voronezh State University, Universitetskaya Square 1, 394000 Voronezh, Russia

3 Military Aviation Engineering University, 54 Old Bolshevikov ST, 394064 Voronezh, Russia lattice thermal conductivity) and the creation of a structure, through the formation of a composite substructure, which includes nanocontacts between the macrocrystallites of a bulk phase [10]. The possible increase of $Z T$ through the variation of elemental composition is almost exhausted, while increasing $Z T$ by exploiting its structural dependence has a long-term perspective [11].

To date, several methods have been developed for obtaining bulk thermoelectric materials. Most of them such as the condensation in an inert gas atmosphere [12]; plasma chemical method [13]; chemical synthesis [14] followed by spark plasma sintering [15]; the grinding powders in a ball mill [16] are based on the compacting of powders with an appropriate composition. The main challenge in these approaches is to create the synthesis conditions of homogeneous bulk thermoelectric materials, not only maximizing the anisotropy of electrophysical properties of the bismuth telluride rhombohedral lattice but also increasing the mechanical properties (taking into account the low strength of these materials along the cleavage planes) [17]. The mechanical strength and adhesion of the switching layers are especially important for the production of thermoelectric generator modules, whose branches experienced high-temperature gradients [18]. As shown in [19], the mechanical polishing followed by the photon treatment (PT) through the irradiation of semiconductor surfaces by the powerful xenon lamps increases the 
adhesion of a contact metallization to the semiconductor branches. PT initiates the recrystallization processes, which leads to the formation of a nanocrystalline structure in the subsurface layers of semiconductors [20]. It was shown that the formation of 15-20-nm-thick nanoplates (defects) in the $\mathrm{Sb}_{2-x} \mathrm{Bi}_{x} \mathrm{Te}_{3}$ structure is accompanied by a $15 \%$ increase in $Z T$, compared to the "standard" material [21]. As demonstrated by calculations, in the nanostructured materials with the tunnel contacts between the particles or layers, the main mechanism of charge transfer is the quantum tunneling between nanoparticles. Besides, the phonon thermal conductivity through the barrier layers is absent [22]. Thus, the present work aimed to establish the PT treatment effect on the thermoelectric figure of merit of the $\mathrm{Bi}_{2} \mathrm{Te}_{3}-\mathrm{Bi}_{2} \mathrm{Se}_{3}$ solid solutions through the modification of the sample's surface layer.

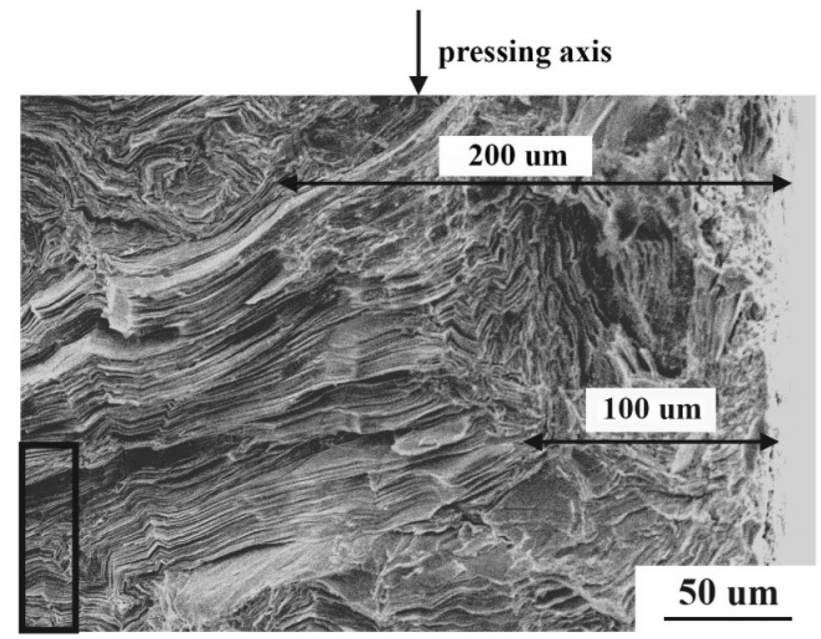

Fig. 1 The cross-sectional SEM image of the semiconductor material sample obtained in the process of hot pressing (the selected fragment is the end of the plate, cut out for the experiment)

\section{Materials and methods}

The original semiconductor samples based on $\mathrm{Bi}_{2} \mathrm{Te}_{3}-\mathrm{Bi}_{2} \mathrm{Se}_{3}$ solid solution (n-type) were obtained by the cold pressing, followed by hot isostatic pressing of powders with the corresponding composition at $T=670 \mathrm{~K}$ with the subsequent annealing at $T=570 \mathrm{~K}$ for $24 \mathrm{~h}$ in an argon atmosphere. Figure 1 shows the cross-sectional SEM image of a semiconductor material synthesized by this method. In the isostatic pressing process, the volume structure of the material is ordered. The crystallites are preferably oriented and the $c$ axis coincides with the direction of the punch movement (see Fig. 1). The structure of the workpiece at a distance of $100-200 \mu \mathrm{m}$ from the surface contacting with the wall of the matrix (mold) during pressing is different.

As follows from Fig. 1, the structure of a subsurface layer (up to $200 \mu \mathrm{m}$ thick) contains the fractures and flat defects, resulting from the sliding of crystallites along the cleavage planes. The texture is formed by deformation in the polycrystalline sample (the crystallites are mainly oriented perpendicular to the pressing axis (see the selected fragment in Fig. 1). The texture formation occurs due to the plastic flow of the material (extrusion) along the mold surface. To investigate the heat conductivity, the as-prepared semiconductor billet was cut out into plates of $10 \times 10 \times 3 \mathrm{~mm}$ in size to ensure that their surface was parallel to the pressing axis (the selected fragment in Fig. 1 is the cut-out end).

The PT treatment of the sample's surface was carried out by the UOL.P-1M experimental setup. The chamber is shown schematically in Fig. 2a.

The PT was alternately carried out by irradiation of both sides of a sample with the powerful radiation (spectral range $\lambda=0.2-1.2 \mu \mathrm{m}$, Fig. $2 \mathrm{~b}$ ) in an Ar atmosphere under the following modes: single and double irradiation with a packet of pulses with a duration of $10^{-2} \mathrm{~s}$ for $1.4 \mathrm{~s}$ (which corresponds to the radiation energy $\left(E_{\mathrm{I}}\right) \sim 140 \mathrm{~J} / \mathrm{cm}^{2}$ supplied to the sample).
Fig. 2 The PT chamber (a) and the xenon lamp emission spectra of (b): 1, a sample; 2 , xenon lamps; 3 , quartz tubes; 4 , sealing

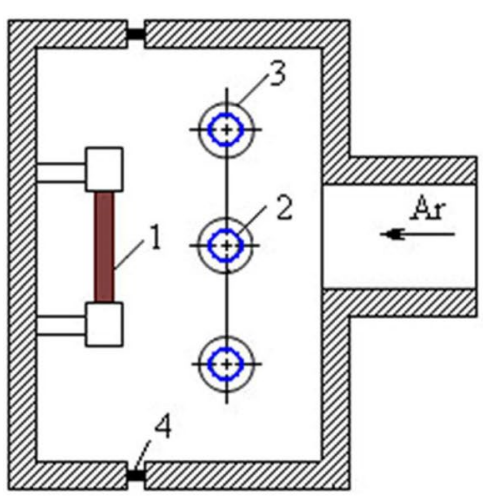

a

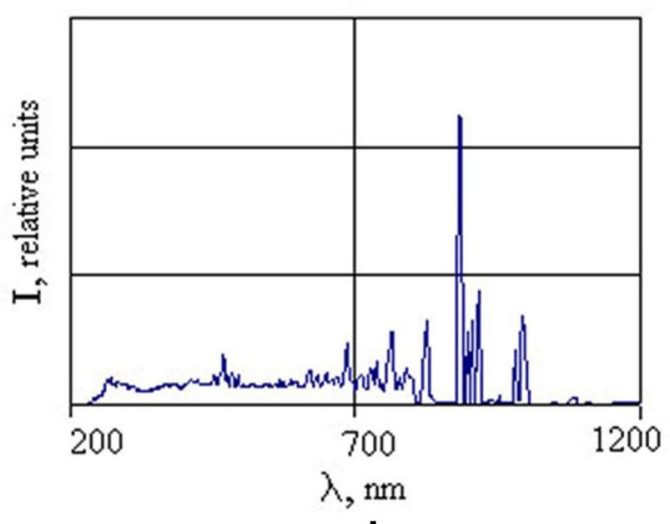


The structural analysis was performed using a high-resolution transmission electron microscope (TEM, FEI Titan300), a scanning electron microscope (SEM, FEI HELIOS Nanolab) and a powder diffractometer (XRD, Bruker D2 PHASER with a $\mathrm{Cu} \mathrm{K} \alpha$ source) operated at $40 \mathrm{kV}$ and $35 \mathrm{~mA}$. The samples were prepared by the cross-section technique, using a focused ion beam (FIP $\mathrm{Ga}^{+}$with the energy of $30 \mathrm{keV}$ ). The energy-dispersive $\mathrm{X}$-ray microanalysis (EDAM for SEM and transmission (STEM) electron microscopes) was used to map an elemental composition over the sample surface and the concentration profile of elements as a function of depth was obtained. STEM images were obtained by registering the low- and high-angle scattered electrons. The first method allows analyzing the grain substructure, and the second one reveals pores, grain boundaries and their location throughout the layer thickness.

The thermal conductivity of the studied samples before and after PT was determined by a laser flash method with the use of a Netzsch LFA 467.

\section{Results and discussion}

Figure 3 shows XRD patterns of the $\mathrm{Bi}_{2} \mathrm{Te}_{3}-\mathrm{Bi}_{2} \mathrm{Se}_{3}$ samples (n-type) before and after PT.

It follows from the XRD data that the phase composition of the samples corresponds to a non-homogeneous solid solution $\mathrm{Bi}_{2} \mathrm{Te}_{3-x} \mathrm{~S}_{x}(0.7 \leq x \leq 1.0)$, attributed to a rhombohedral lattice $(R \overline{3} \mathrm{~m})$ with the lattice parameters $a$ and $c$ ranging from 0.4300 to $0.4339 \mathrm{~nm}$ and from 3.000 to $3.022 \mathrm{~nm}$, respectively. The XRD spectra of the samples after PT differ from those for the as-prepared structures of the initial ones.
The peaks' intensity redistribution and a change in their width for the samples after PT can be caused by the surface layer recrystallization, leading to a decrease in stresses and the formation of grains with arbitrary mutual orientation. It is because the subsurface layer of the sample heats up to a temperature of about $800 \mathrm{~K}$ in the PT process.

Although the second PT does not change the diffraction maxima intensity, it leads to a decrease in the peak's width, caused by an increase in the grain size during the recrystallization of the subsurface layer.

Figure 4 shows SEM images of the surface of a semiconductor material before and after doubly PT.

As follows from Fig. 4, the surface morphology of the semiconductor material is transformed greatly during the PT process. The initial surface (Fig. 4a) is characterized by the isotropic relief inhomogeneities, sized from 50 to $150 \mathrm{~nm}$, resulting from the deformation compacting of the powder during the pressing process. The PT modifies the surface (Fig. 4b) with the formation of the anisotropic inhomogeneities with lateral dimension up to $1.5 \mu \mathrm{m}$, originated from the recrystallization of a submicron subsurface layer. The ultrafine particles (up to $30 \mathrm{~nm}$ in size) observed on the surface are sublimated from the material in the process of PT due to the condensation of volatile components.

Figure 5 shows the cross-sectional STEM, TEM images and the concentration profile of FIP elements for the semiconductor material after the doubly PT.

The structure of the sample surface layer with a thickness of $\sim 500 \mathrm{~nm}$ after PT (Fig. 4a, b) differs from that in the bulk. A large-block polycrystalline structure with crystallites from 0.5 to $3 \mu \mathrm{m}$ in size is observed at a distance of more than $1 \mu \mathrm{m}$ from the surface. The substructure is characterized by
Fig. 3 XRD patterns of the studied samples before (1) and after the first PT (2)

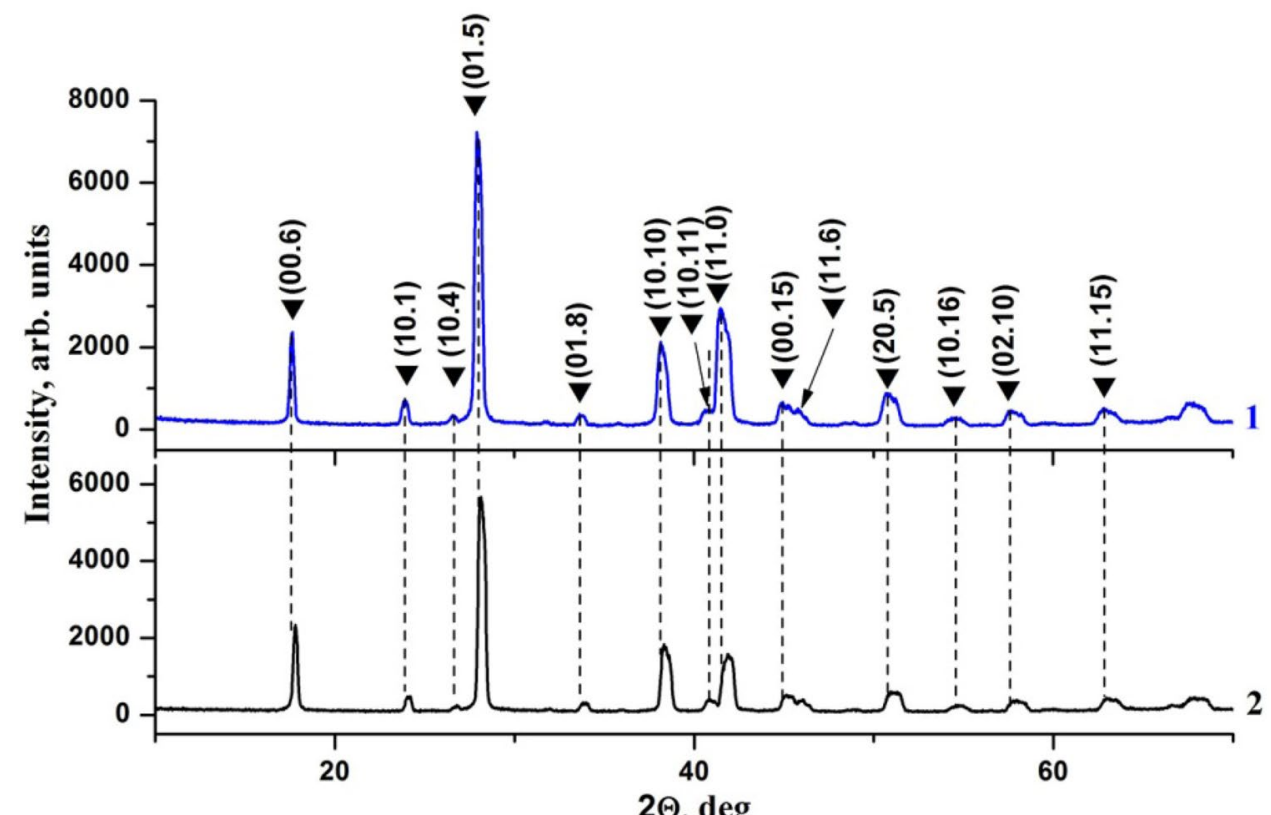

$2 \Theta, \operatorname{deg}$ 


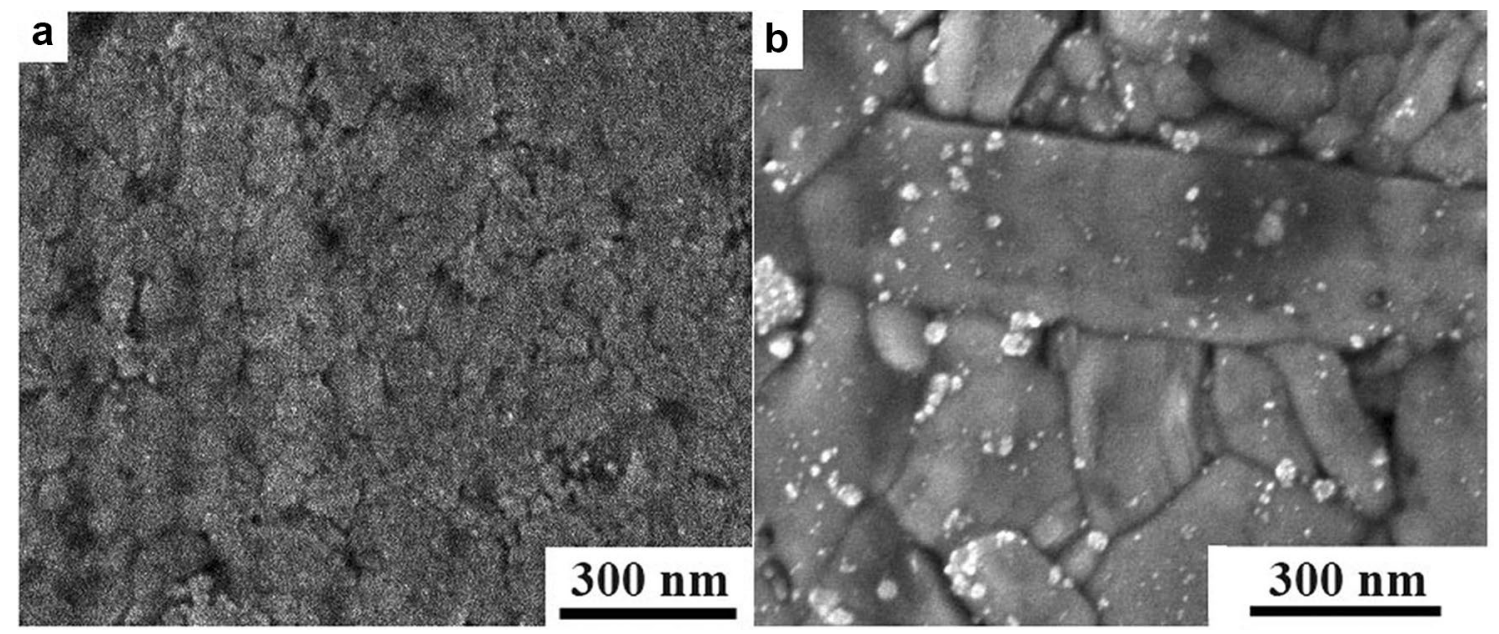

Fig. 4 SEM images of the surface of a semiconductor material before (a) and after doubly PT (b)
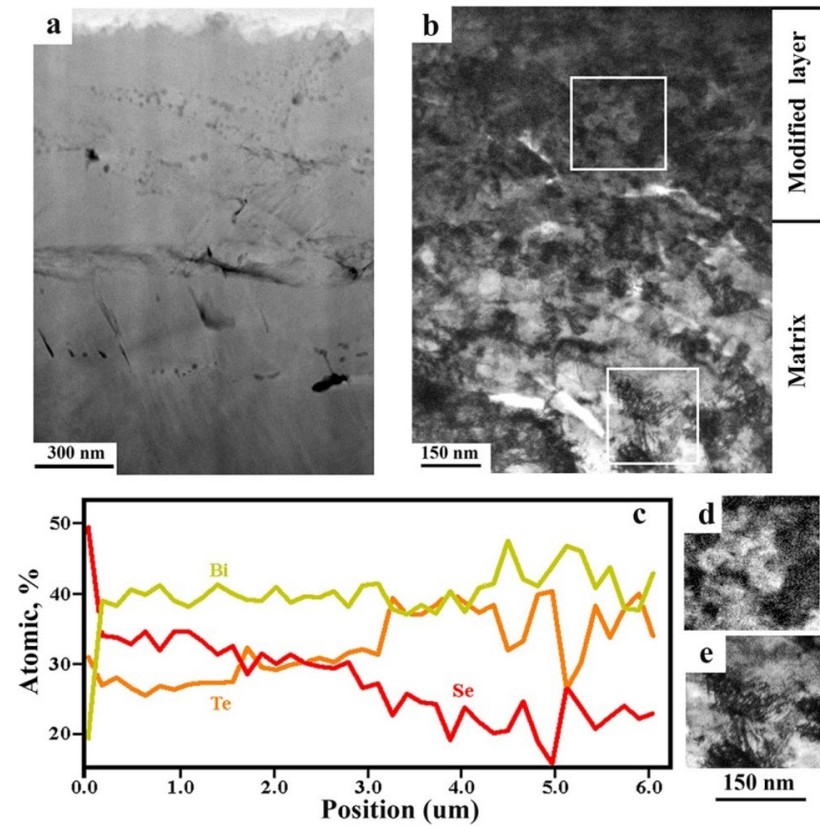

Fig. 5 The cross-sectional STEM (a), TEM (b) images and the concentration profiles of elements $(\mathbf{c})$ after the double PT $\left(E_{\mathrm{I}} \sim 140 \mathrm{~J} /\right.$ $\mathrm{cm}^{2}$ ). The enlarged fragments of STEM, TEM images are shown in figures $\mathbf{d}$ and $\mathbf{e}$

flat and globular defects. The flat defects include a system of parallel lamellar inclusions with a width ranging from $50 \mathrm{~nm}$ to $1 \mu \mathrm{m}$ and cracks of the same size. The globular inhomogeneities do not exceed $50 \mathrm{~nm}$ in size. The structure of the subsurface layer (modified in the phase transition process) is heterogeneous (Fig. 4a). Both the large arbitrary oriented crystallites ranging from 0.5 to $3 \mu \mathrm{m}$ in size and nanocrystals with the size of $\sim 15 \mathrm{~nm}$ are observed on the treated surface (see Fig. 4a). The modified layer demonstrates the high density $\left(\sim 2 \times 10^{10} / \mathrm{cm}^{2}\right)$ of globular defects (pores, inclusions), ranging in size from 15 to $40 \mathrm{~nm}$. As seen in Fig. 4b, the crystallites (sized from 40 to $60 \mathrm{~nm}$ ) in the top-most layer contain no dislocations and demonstrate a "core-shell" spherical morphology (see Fig. 5d). At a depth of more than $1.5 \mu \mathrm{m}$, the crystallites are significantly larger $(d>250 \mathrm{~nm})$ and contain a network of dislocations with a linear density of about $1 \times 10^{6} \% \mathrm{~cm}$ (see Fig. 5e).

It follows from the concentration profiles of elements in the samples after the PT treatment (Fig. 5c) that the subsurface region of $3 \mu \mathrm{m}$ is enriched with Se and depleted by Te compared to the bulk material, where the elemental composition is close to that of the $\mathrm{Bi}_{2} \mathrm{Te}_{3-x} \mathrm{Se}_{x}$ solid solution for $x \sim 1$. The change in the elemental composition is caused by diffusion triggered by the high temperature at the sample surface and occurring during the PT process [19]. Some authors found that Te sublimation occurs in the PT process, leading to the formation of various defects (vacancies, nanopores) [20].

Figure 6 shows the thermal conductivity as a function of temperature for the studied samples. Experimental data shows that both the single and doubly PT treatments decrease the thermal conductivity. As regards the double PT, this decline is more prominent $(4-5 \%)$ for the entire temperature range studied.

According to [23], the thermoelectric figure of merit can be calculated as $Z T=\frac{\sigma \alpha^{2}}{\lambda} T$ (where $T, \sigma, \alpha$ and $\lambda$ are the absolute temperature, electrical conductivity, the Seebeck coefficient, and the thermal conductivity, respectively). Figure 7 shows how the calculated thermoelectric figure of merit of the studied samples varies with temperature taking into account the measured data for the Seebeck coefficient and electrical conductivity. As seen from Fig. 7, the magnitude of thermoelectric figure of merit does not change after the first PT despite the decrease in the heat conduction. It is because the conductivity $\sigma$ decreases by $2-5 \%$ depending 


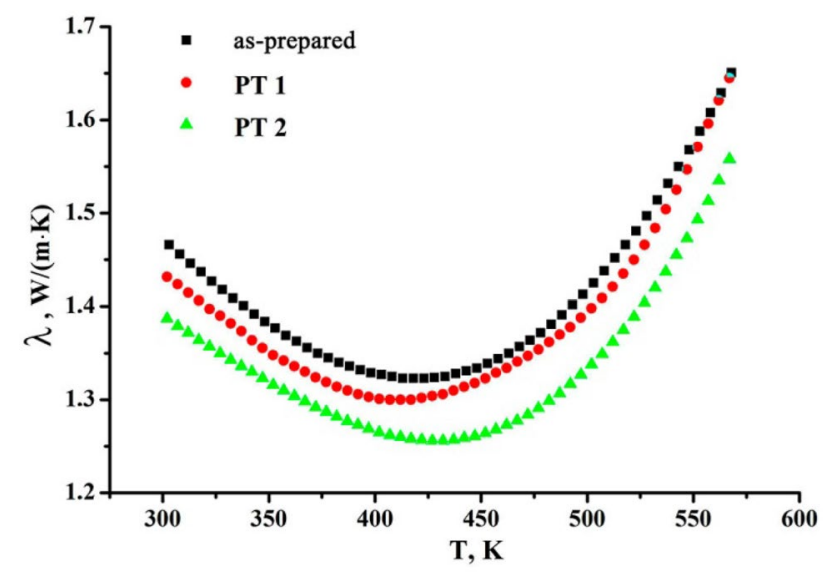

Fig. 6 Temperature dependence of the thermal conductivity of the asprepared sample, and the samples after the single PT (PT1 curve) and double PT (PT2 curve)

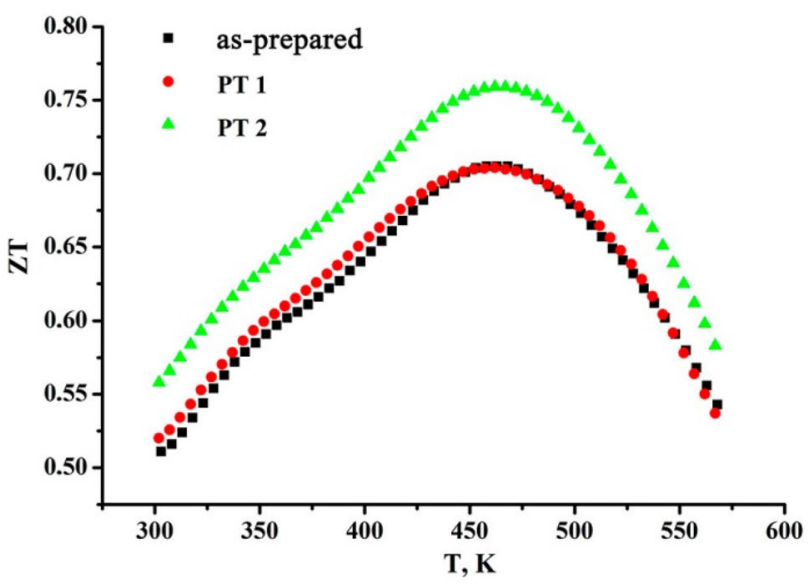

Fig. 7 Temperature dependence of the thermoelectric figure of merit before (as-prepared curve), after the single PT (PT1 curve) and double PT (PT2 curve) of the studied samples

on temperature and the Seebeck coefficient $\alpha$ increases by $2.5 \%$ after the first PT. As was mentioned above, the size of the crystallites in the surface layer decreases under the first PT. Consequently, the observed changes in the material properties are caused by the change in the structure of a subsurface region.

The double PT of the studied samples leads to an increase in their $Z T$ by $8 \%$. In this case, the value of the thermal conductivity decreases by $\sim 8 \%$, and the $\sigma$ and $\alpha$ magnitudes change slightly. The Seebeck coefficient and conductivity increase by $1 \%$ and $2.5 \%$, respectively, relative to the corresponding parameters of the studied samples after the first PT. Our attempts to increase the number of PT cycles lead to decreasing the figure of merit which resulted from the grain size increase induced by PPT.
Figure 8 shows the Seebeck coefficient as a function of temperature for the studied samples.

As seen from Fig. 8, the PT increases the Seebeck coefficient $\alpha$ (in magnitude). The single PT declines $\alpha$ by $2.5 \%$. The second PT conducted with a higher pulse intensity further decreases $\alpha$ by $1 \%$. The Seebeck coefficient is varied through the electronic density of states or by increasing the relaxation time through the scattering mechanisms. It was demonstrated theoretically that the band bending at the grain boundaries in polycrystalline materials scatter the low-energetic carriers, increasing $\alpha$ [24]. Apparently, this mechanism is responsible for the increase in the Seebeck coefficient magnitude in our case.

Figure 9 demonstrates the electrical conductivity as a function of temperature for the studied samples.

The electrical conductivity depends on the carrier concentration and mobility. Taking into account that the PT affects the mobility $\mu$ greater than the concentration, we can conclude that in our case the PT changes the $\mu$. In the polycrystalline materials, the scattering associated with inhomogeneities (grain boundaries, dislocations, point defects) contributes the mobility greatly. Thus, in our case the PT produces more scattering centers, reducing the carrier mobility and consequently the electrical conductivity. The second PT leads to the material re-crystallization, decreasing the scattering phenomena in the studied samples.

The quality factor increase after the second PT is also associated with the change of a crystal structure in the surface layers. As shown above, during the PT treatment of both sides of the semiconductor plates, a sandwich occurs. It contains the $\mathrm{Bi}_{2} \mathrm{Te}_{3-x} \mathrm{Se}_{x}$ phase on the bulk and having a textured layered structure. In contrast, the near-surface regions ( 570-600 nm) contain the $\mathrm{Bi}_{2} \mathrm{Te}_{3-x} \mathrm{Se}_{x}$ phase with a heterogeneous structure composed of the nanocrystals $(d=15 \mathrm{~nm})$

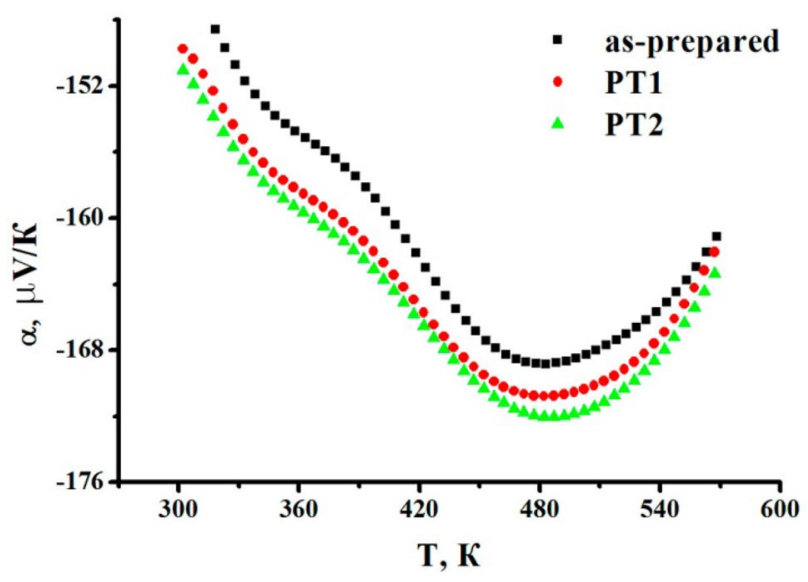

Fig. 8 The Seebeck coefficient as a function of temperature for asprepared samples, after the single PT (PT1 curve) and double PT (PT2 curve) of the studied samples 


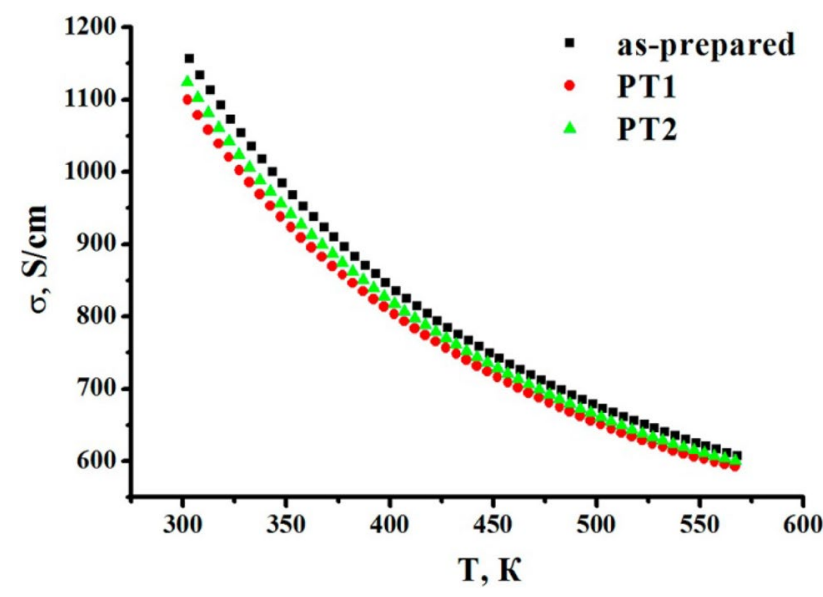

Fig. 9 The electrical conductivity as a function of temperature for as-prepared samples, after the single PT (PT1 curve) and double PT (PT2 curve) of the studied samples

and the arbitrarily oriented grains in the form of plates with the width ranging from 0.1 to $0.4 \mu \mathrm{m}$ and the length from 0.6 to $4 \mu \mathrm{m}$. As a result, the crystalline structure is formed near the sample surface, with the gradient in average crystallite size, directed from the surface towards the material bulk. The average grain size varies from 50 to $300 \mathrm{~nm}$ at a distance of $1-2 \mu \mathrm{m}$ from the surface. Thus, the fraction of grain boundaries in the bulk of the semiconductor differs by $30-40$ times relative to that near the surface. It was reported [20, 25 ] that an increase in $Z T$ in the nanostructured thermoelectric materials is originated from the decrease in the thermal conductivity caused by the phonon scattering on the nanosized inhomogeneities. In our case, the grain boundaries act as such inhomogeneities, occurring due to the segregation of impurity atoms and selenium that diffuses in the PT process. Due to the low electrical conductivity of selenium and the high fraction of grain boundaries, the $\mathrm{Bi}_{2} \mathrm{Te}_{3-x} \mathrm{Se}_{x}$ crystallites can act as the macroscopic area within a semiconductor, having nano-size contacts in a matrix of low conducting material. Consequently, in the PT process, a gradient nanostructured region composed of the nanocrystals and large $\mathrm{Bi}_{2} \mathrm{Te}_{3-x} \mathrm{Se}_{x}$ crystals with the tunneling contacts is created in the material.

The effective properties of $\mathrm{Bi}_{2} \mathrm{Te}_{3}$-based composites, with the nano-size contacts between macrocrystallites of the bulk phase, were theoretically studied in [7]. The proposed model of such nanostructured composite implies the occurrence of a tunnel contact at the boundary of the bulk and nanocrystalline phases. In the framework of this model and based on the field approximation, the effective values of the thermoelectric power, heat, and electrical conductivity, as well as the thermoelectric figure of merit, were calculated. It was found that when the tunnel contact width rises from $0.5 \mathrm{~nm}$ to $0.8 \mathrm{~nm}$, the electron heat conductivity decreases by 3 times, the electrical conductivity declines, and the thermopower increases by about $10 \%$. As a result, the authors reported the increase in $Z T$ values up to 3.52. In our case, the PT modifies the only subsurface layers of the studied samples. Thus, the quantitative changes of the determined quantities were lower despite the qualitative coincidence with the measured results. Consequently, in our case, the increase in $Z T$ can also be associated with the tunnel contact occurrence at the interface between the crystalline (the bulk of material) and nanocrystalline (subsurface layers of the material) phases.

\section{Conclusions}

The modified layer formed under the PT of semiconductor plates has an inhomogeneous nanocrystalline structure with an arbitrary nanocrystals' orientation. By contrast, the bulk material demonstrates the stable elemental, phase composition and the large-block crystalline structure with an extrusion texture. The subsurface layers of semiconductor plates based on $\mathrm{Bi}_{2} \mathrm{Te}_{3}-\mathrm{Bi}_{2} \mathrm{Se}_{3}$ (n-type) solid solution occur in the process of $\mathrm{PT}$, due to the recrystallization and modification. The gradient nanostructured area of the material is created, where the nanocrystals and large $\mathrm{Bi}_{2} \mathrm{Te}_{3-x} \mathrm{Se}_{x}$ crystals represent a composite with the tunnel contacts. The formation of a gradient of the average grain size in the surface layers decreases the thermal conductivity and increases the thermoelectric figure of merit of the PT-treated material by $8 \%$.

Acknowledgements The equipment of the Central chernozem Center for Shared Use and the Center for Shared Use of Voronezh State Technical University was used. This work was supported by the Ministry of Education of the Russian Federation (Decree of the government of the Russian Federation: Agreement \#03.G25.31.0246).

\section{Compliance with ethical standards}

Conflict of interest The authors declare that they have no conflict of interest.

Open Access This article is licensed under a Creative Commons Attribution 4.0 International License, which permits use, sharing, adaptation, distribution and reproduction in any medium or format, as long as you give appropriate credit to the original author(s) and the source, provide a link to the Creative Commons licence, and indicate if changes were made. The images or other third party material in this article are included in the article's Creative Commons licence, unless indicated otherwise in a credit line to the material. If material is not included in the article's Creative Commons licence and your intended use is not permitted by statutory regulation or exceeds the permitted use, you will need to obtain permission directly from the copyright holder. To view a copy of this licence, visit http://creativecommons.org/licenses/by/4.0/. 


\section{References}

1. Hsu, K.F., Loo, S., Guo, F., Chen, W., Dyck, J.S., Uher, C., Hogan, T., Polychroniadis, E.K., Kanatzidis, M.G., Vashaee, D., Chen, X., Liu, J., Dresselhaus, M.S., Chen, G., Ren, Z.: Cubic $\mathrm{AgPbmSbTe}+\mathrm{m}$ : bulk thermoelectric materials with high figure of merit. Science 303, 818-821 (2004). https://doi.org/10.1126/ science. 1092963

2. Kashiwagi, M., Hirata, S., Harada, K., Zheng, Y., Miyazaki, K., Yahiro, M., Adachi, C.: Enhanced figure of merit of a porous thin film of bismuth antimony telluride. Appl. Phys. Lett. 98, 023114 (2011). https://doi.org/10.1063/1.3543852

3. Xie, W., Tang, X., Yan, Y., Zhang, Q., Tritt, T.M.: Unique nanostructures and enhanced thermoelectric performance of melt-spun BiSbTe alloys. Appl. Phys. Lett. 94, 102111 (2009). https://doi. org/10.1063/1.3097026

4. Zhang, Y., Jia, X., Deng, L., Guo, X., Sun, H., Sun, B., Liu, B., Ma, H.: Evolution of thermoelectric properties and anisotropic features of $\mathrm{Bi}_{2} \mathrm{Te}_{3}$ prepared by high pressure and high temperature. J. Alloys Compd. 632, 514-519 (2015). https://doi.org/10.1016/J. JALLCOM.2015.01.271

5. Lognoné, Q., Gascoin, F.: On the effect of carbon nanotubes on the thermoelectric properties of $n-\mathrm{Bi}_{2} \mathrm{Te}_{2.4} \mathrm{Se}_{0.6}$ made by mechanical alloying. J. Alloys Compd. 635, 107-111 (2015). https://doi. org/10.1016/j.jallcom.2015.02.055

6. Mori, T., Priya, S.: Materials for energy harvesting: at the forefront of a new wave. MRS Bull. 43, 176-180 (2018). https://doi. org/10.1557/mrs.2018.32

7. Petsagkourakis, I., Tybrandt, K., Crispin, X., Ohkubo, I., Satoh, N., Mori, T.: Thermoelectric materials and applications for energy harvesting power generation. Sci. Technol. Adv. Mater. 19, 836862 (2018). https://doi.org/10.1080/14686996.2018.1530938

8. Dagdeviren, C., Li, Z., Wang, Z.L.: Energy harvesting from the animal/human body for self-powered electronics. Annu. Rev. Biomed. Eng. 19, 85-108 (2017). https://doi.org/10.1146/annur ev-bioeng-071516-044517

9. Ioffe, A.F.: Semiconductor Thermoelements, and Thermoelectric. Cool-ingInfosearch Ltd., London (1957)

10. Snarskii, A.A., Sarychev, A.K., Bezsudnov, I.V., Lagarkov, A.N.: Thermoelectric figure of merit for bulk nanostructured composites with distributed parameters. Semiconductors 46, 659-665 (2012). https://doi.org/10.1134/S106378261205020X

11. Mori, T.: Novel principles and nanostructuring methods for enhanced thermoelectrics. Small 13, 1702013 (2017). https://doi. org/10.1002/smll.201702013

12. Winkler, M., Liu, X., König, J.D., Buller, S., Schürmann, U., Kienle, L., Bensch, W., Böttner, H.: Electrical and structural properties of $\mathrm{Bi}_{2} \mathrm{Te}_{3}$ and $\mathrm{Sb}_{2} \mathrm{Te}_{3}$ thin films grown by the nanoalloying method with different deposition patterns and compositions. J. Mater. Chem. 22, 11323 (2012). https://doi.org/10.1039/c2jm3 $0363 \mathrm{a}$

13. Gusev, A.I., Rempel, A.A.: Nanocrystalline Materials. Cambridge International Science Pub, Cambridge (2004). https://www.world cat.org/title/nanocrystalline-materials/oclc/1037714680

14. Hui-Fang, H., Zhi-Quan, C.: Positron annihilation studied defects and their influence on thermal conductivity of chemically synthesized $\mathrm{Bi}_{2} \mathrm{Te}_{3}$ nanocrystal. Acta Phys. Sin. 2015, 64 (2015). https://doi.org/10.7498/aps.64.207804

15. Ge, Z.-H., Ji, Y.-H., Qiu, Y., Chong, X., Feng, J., He, J.: Enhanced thermoelectric properties of bismuth telluride bulk achieved by telluride-spilling during the spark plasma sintering process. Scr. Mater. 143, 90-93 (2018). https://doi.org/10.1016/J.SCRIP TAMAT.2017.09.020

16. Dannangoda, G.C., Key, C., Sumets, M., Martirosyan, K.S.: Transition of p- to n-Type conductivity in mechanically activated bismuth telluride. J. Electron. Mater. 47, 5800-5809 (2018). https:// doi.org/10.1007/s11664-018-6469-1

17. Bublik, V.T., Voronin, A.I., Vygovskaya, E.A., Ponomarev, V.F., Tabachkova, N.Y., Toropova, O.V.: Analysis of anisotropy of properties on the basis of studies of texture of coarse-grained ingots of thermoelectric materials. Inorg. Mater. 47, 1563-1568 (2011). https://doi.org/10.1134/S0020168511140044

18. Hao, F., Qiu, P., Tang, Y., Bai, S., Xing, T., Chu, H.-S., Zhang, Q., Lu, P., Zhang, T., Ren, D., Chen, J., Shi, X., Chen, L.: High efficiency $\mathrm{Bi}_{2} \mathrm{Te}_{3}$ - based materials and devices for thermoelectric power generation between 100 and $300^{\circ} \mathrm{C}$. Energy Environ. Sci. 9, 3120-3127 (2016). https://doi.org/10.1039/C6EE02017H

19. Belonogov, E.K., Dybov, V.A., Kostyuchenko, A.V., Kushev, S.B., Sanin, V.N., Serikov, D.V.: Increase in the adhesive properties of commutation layers on semiconductor p-type branches of thermoelectric generator batteries. Condens. Matter Interfaces 20, 553 (2018)

20. Belonogov, E., Dybov, V., Kostyuchenko, A., Kushev, S., Sericov, D., Soldatenko, S.: Effect of pulsed photon treatment on the mechanical properties of semiconductor thermoelectric legs, based on $\mathrm{Bi}_{2} \mathrm{Te}_{3}-\mathrm{Bi}_{2} \mathrm{Se}_{3}$ solid solutions, and the adhesion of switching layers. J. Surf. Investig. X-Ray Synchrotron Neutron Tech. 13, 371-377 (2019)

21. Scheele, M., Oeschler, N., Veremchuk, I., Reinsberg, K.-G., Kreuziger, A.-M., Kornowski, A., Broekaert, J., Klinke, C., Weller, H.: ZT enhancement in solution-grown $\mathrm{Sb}_{(2-\mathrm{x})} \mathrm{Bi}_{\mathrm{x}} \mathrm{Te}_{3}$ nanoplatelets. ACS Nano 4, 4283-4291 (2010). https://doi. org/10.1021/nn1008963

22. Bulat, L.P., Pshenă-Severin, D.A.: Effect of tunneling on the thermoelectric efficiency of bulk nanostructured materials. Phys. Solid State 52, 485-492 (2010). https://doi.org/10.1134/S1063 783410030078

23. Ioffe, A.F.: Physics of Semiconductors. Taylor and Francis, London (1960)

24. Faleev, S.V., Léonard, F.: Theory of enhancement of thermoelectric properties of materials with nanoinclusions. Phys. Rev. B 77, 214304 (2008). https://doi.org/10.1103/PhysRevB.77.214304

25. Dmitriev, A.V., Zvyagin, I.P.: Current trends in the physics of thermoelectric materials. Phys. Usp. 53, 789-803 (2010). https:// doi.org/10.3367/UFNe.0180.201008b.0821

Publisher's Note Springer Nature remains neutral with regard to jurisdictional claims in published maps and institutional affiliations. 